\title{
Prevention of Ischemia-Reperfusion Injury in Human Kidney Transplantation: A Meta-Analysis of Randomized Controlled Trials
}

\author{
Fariba Tohidinezhad (iiD ${ }^{1}$, Saeid Eslami (iD) ${ }^{2}$, Saba Vakili ${ }^{3}$, Mohsen Aliakbarian ${ }^{4}$ and Mahmoud \\ Tavakkoli ${ }^{5, *}$ \\ ${ }^{1}$ Department of Medical Informatics, Faculty of Medicine, Mashhad University of Medical Sciences, Mashhad, Iran \\ ${ }^{2}$ Pharmaceutical Research Center, Pharmaceutical Research Institute, Mashhad University of Medical Sciences, Mashhad, Iran \\ ${ }^{3}$ Genetics Research Center, Faculty of Medicine, Mashhad University of Medical Sciences, Mashhad, Iran \\ ${ }^{4}$ Surgical Oncology Research Center, Faculty of Medicine, Mashhad University of Medical Sciences, Mashhad, Iran \\ ${ }^{5}$ Kidney Transplantation Complications Research Center, Faculty of Medicine, Mashhad University of Medical Sciences, Mashhad, Iran \\ Corresponding author: Kidney Transplantation Complications Research Center, Faculty of Medicine, Mashhad University of Medical Sciences, Mashhad, Iran. Tel/Fax: \\ +98-5131802630, Email: tavakkolim@mums.ac.ir
}

Received 2020 February 03; Accepted 2020 March 06.

\begin{abstract}
Context: Using the marginal and expanded criteria organs increases the risk of ischemia-reperfusion injury(IRI), which remains unavoidable concerning issue after kidney transplantation (KT). While numerous trials have tested novel pharmaceutical approaches on animal models, little attempt has been made to assess the reproducibility of those results in the human setting. This study aimed to conduct a systematic review and meta-analysis to identify and abstract existing prophylactic strategies performed to reduce the risk of IRI after KT in human clinical trials.

Evidence Acquisition: A comprehensive search was performed in MEDLINE, EMBASE, and Science Citation Index Expanded to detect relevant clinical trials until January 1,2019. Two independent reviewers assessed the study eligibility, abstracted data, and evaluated the risk of bias. The prevention strategies in the included studies were categorized by one urologist. The fixed or random-effects model was selected based on the level of heterogeneity between studies in each category. The Cochran Q-test and I2 statistics were used to quantify the level of heterogeneity. The risk ratio (RR) of the delayed graft function (DGF) was calculated as the summary effect size of the primary outcome.

Results: A total of 33 randomized controlled trials (31,334 patients) were categorized into seven groups based on the preventive hypotheses. Significant effects on DGF were observed in favor of the machine perfusion organ storage $(\mathrm{RR}=0.73 ; 95 \% \mathrm{CI}=0.7$ to 0.76 ; $\left.I^{2}=0 \%\right)$ and use of antioxidant agents ( $R R=0.6 ; 95 \% C=0.46$ to $\left.0.78 ; I^{2}=33 \%\right)$. There were no significant effects by innate inhibitors $\left(\mathrm{RR}=0.86 ; 95 \% \mathrm{CI}=0.6\right.$ to $\left.1.23 ; \mathrm{I}^{2}=58 \%\right)$, anti-inflammatory agents $\left(\mathrm{RR}=0.86 ; 95 \% \mathrm{CI}=0.62\right.$ to $\left.1.19 ; \mathrm{I}^{2}=0 \%\right)$, calcium-channel blockers (CCBs) $\left(\mathrm{RR}=0.67 ; 95 \% \mathrm{CI}=0.3\right.$ to $\left.1.49 ; \mathrm{I}^{2}=76 \%\right)$, conditioning $\left(\mathrm{RR}=0.83 ; 95 \% \mathrm{CI}=0.59\right.$ to $1.16 ; \mathrm{I}^{2}=16 \%$ ), and donor management techniques $\left(\mathrm{RR}=0.88 ; 95 \% \mathrm{CI}=0.64\right.$ to $\left.1.2 ; \mathrm{I}^{2}=57 \%\right)$.

Conclusions: This review supports the use of machine perfusion organ storage and administration of antioxidant agents. However, the clinical application of innate inhibitors, anti-inflammatories, CCBs, conditioning, and donor management techniques needs further investigations in large scales (PROSPERO number: CRD42019132985).
\end{abstract}

Keywords: Ischemia-Reperfusion Injury, Kidney Transplantation, Graft Outcome, Delayed Graft Function, Humans

\section{Context}

Kidney transplantation (KT) is the most promising modality of treatment to improve the survival and quality of life of patients with irreversible kidney failure. However, the organ shortage limits its widespread use and clinical application. In recent decades, the utilization of the marginal and expanded criteria organs, including donation after circulatory death, has been employed to increase the organ pool $(1,2)$. Organs from cardiac death donors are associated with long mean ischemia time starting from the circulatory arrest of the donor to the end of the cold preservation phase before transplantation (3). The ischemiarelated complications after deceased and living donations are also controversial with lower incidence rates.

The ischemia-reperfusion injury (IRI) is unavoidable tissue damage that occurs when the blood supply returns to the kidney after a period of anoxia or hypoxia. Reduced metabolic supply during prolonged blood flow distur- 
bance causes severe capillary damage. Subsequent reperfusion not only does not restore the normal condition, but also increases the damage by activating the innate immune system and the programmed cell death process (4, 5).

Ischemia-reperfusion injury is a major cause of acute kidney injury that affects short- and long-term outcomes $(6,7)$. It has been demonstrated that delayed graft function (DGF) is a manifestation of IRI that is clinically defined as the "need for dialysis in the first week after transplant, once hyperacute rejection, vascular, and urinary tract complications are ruled out" (8). About $35 \%$ of first-graft patients and $47 \%$ of regrafted patients experience DGF (9). Delayed graft function occurs as a result of the activation of the innate immune response. Factors that have been found to increase the risk of DGF include donor factors (including older age, cardiac or brain death, and abnormal biopsy findings), recipient factors (including male gender, body mass index of greater than 30, African-American ethnicity, and high panel reactive antibodies), and inappropriate preservation methods.

The exact underlying cellular mechanism of IRI is not completely understood, but dysregulation of energy metabolism, alteration of cellular mitochondria and membranes, and different forms of cell death (e.g. apoptosis, necrosis, or necroptosis) have been observed in in-vivo studies. Since 1985, numerous trials have been performed in small and large animal models (e.g. rat, pig, and monkey) to test novel pharmaceutical agents administrated either intravenously or as an additive to the preservation solution. Previous studies have proven that insights gleaned from animal models can rarely be extrapolated to the human context (10). Clinical trials have been performed in human settings concentrating on different strategies including anti-inflammatory, anti-oxidant, and innate inhibition therapies. The current study abstracts published knowledge from human clinical trials and discusses the effectiveness of the proposed preventive hypotheses.

\section{Evidence Acquisition}

This study was conducted following the preferred reporting items for systematic reviews and meta-analysis (PRISMA) guidelines (11). Moreover, a priori registration of the protocol was done in PROSPERO, an international prospective register of systematic reviews (registration number: CRD42019132985) (12).

\subsection{Data Sources and Search Design}

A comprehensive literature search was performed in MEDLINE (via PubMed), EMBASE (via Scopus), and Science Citation Index Expanded (via Web of Science) from inception until January 1, 2019. The search strategy was developed using a Boolean combination of the subject headings or keywords associated with "Kidney", "Transplantation", "Reperfusion”, "Injury”, "Ischemia”, and "Prevention". Searches were limited to human subjects and English language articles. The search terms were re-run on May 30, 2019, to capture potentially eligible studies published after the initial search.

\subsection{Eligibility Criteria and Study Selection}

In this review, we included the original publications of Randomized Controlled trials (RCTs) investigating the effect of an IRI prevention strategy (i.e. pharmaceutical, surgical, organ preservation, etc.) compared with a control group in a cohort of patients undergoing kidney transplantation. All studies including adult or pediatric kidney recipients from either living or deceased donors were included. Following exclusion criteria were applied to exclude irrelevant studies: meta-analyses, review articles, case reports, conference papers, abstracts, editorial letters, and in-vivo/in-vitro studies. The search results were entered in reference manager software. After deduplication, two researchers (FT and MT) independently assessed the eligibility of the citations by title and abstract. The full-texts of the relevant studies were then evaluated to be included in the final synthesis. In case of disagreement, the final decision was made after consultation with the third reviewer (SE). Once the reviewers encountered duplicate studies on an overlapping study population, the study with the larger sample size was included. The reference list of the included trials and the "Similar Articles" feature in PubMed were also used to identify additional studies.

\subsection{Data Extraction and Management}

One reviewer (with clinical research training) extracted the following data items using a standardized form: publication year, country or region, the number of patients in each study arm, patients' demographics separated for the intervention and control groups (i.e. age and gender distribution), and preventive agent or technique.

The incidence rate of the DGF was considered the primary outcome. Secondary outcomes were serum creatinine, creatinine clearance, urine output, estimated 
glomerular filtration rate (eGFR), and graft/patient survival rates. Once statistical analyses showed significant differences for at least one outcome in favor of the intervention group, the effectiveness variable was considered as "yes". The second reviewer checked for the validity of the data abstraction.

\subsection{Risk of bias and Quality Assessment}

Two investigators (FT and MT) independently assessed the methodological risk of bias using the Cochrane risk of bias tool (13). This tool categorizes the risk of bias as low, high, or unclear across the following domains: random sequence generation (selection bias), allocation concealment (selection bias), selective reporting (reporting bias), blinding of participants and personnel (performance bias), blinding of outcome assessment (detection bias), incomplete outcome data (attrition bias), and other sources of bias (e.g. fraudulent results, funding issues, etc.). We then used the thresholds defined by the Agency for Healthcare Research and Quality (AHRQ) to categorize the quality of studies as good (low risk of bias for all domains), fair (high risk of bias for one domain or unclear description for two domains), or poor (high or unclear risk of bias in two or more domains) (14). Conflicts on risk assessment were resolved by the third investigator (SE).

\subsection{Data Synthesis and Statistical Analyses}

After the tabulation of the included studies, one urologist determined the category of the treatment hypothesis using one of the following terms: donor management, organ storage, anti-inflammatory treatment, antioxidant treatment, innate inhibition, calcium-channel blockers, and conditioning (15). The meta-analysis was conducted when relevant data were available from at least three studies in each category. If the study had more than one intervention or control group, both sample size and number of patients with events were summed across the groups (16). To quantify the heterogeneity between studies in each category, the $\mathrm{I}^{2}$ statistic and $\chi^{2}$ of the Cochran Q-test were calculated (17). The summary effect estimate (risk ratio (RR) and 95\% confidence interval (CI)) of each prevention strategy was computed using the Mantel-Haenszel method with a continuity correction of 0.5 in studies with zero events (18). The fixed or random-effects model was used based on the level of heterogeneity. If a significant level of heterogeneity was detected (significant P value of Q-test or I2 $\geq 50$ ), a random-effects model was used to calculate the summary effect estimate. Otherwise, a fixed-effects model was employed. To assess the publication bias in each category, a funnel plot was used to visualize the effect estimates ( $\mathrm{x}$ axis) against the standard errors (y-axis). Statistical analyses were performed using the "meta" package in the R studio (version 3.5.3, R Core Team, 2019).

\section{Results}

\subsection{Search Results}

Of the 569 articles retrieved, 526 articles were excluded based on the screening of abstracts. A full-text review of the remaining 66 studies (five studies by manual search) resulted in the final inclusion of 38 studies in qualitative synthesis (Figure 1).

\subsection{Characteristics of the Included Studies}

Table 1 describes the key characteristics of the included RCTs. The studies were performed between 1990 and 2018, mostly conducted in the United States (21\%). Eleven studies (28.9\%) evaluated the effect of the oral or infusion administration of an antioxidant agent, mainly recombinant human Superoxide Dismutase (rh-SOD) and N-acetyl-cysteine (NAC) (19-29). Eight studies (21.1\%) assessed the preventive effect of the innate inhibitors (e.g. eculizumab, thymoglobulin, etc.) (30-37). The effect of anti-inflammatory agents, including erythropoietin (EPO), was evaluated in six trials (38-43). Four studies evaluated a type of conditioning technique (i.e., remote ischemic (pre or post) conditioning) (44-47). Moreover, data on the evaluation of calcium-channel blockers (CCBs) (48-50), organ storage techniques (51-53), and donor management approaches (54-56) were separately available in three RCTs.

Around $47.4 \%$ of the studies did not reach a statistically significant level for any of their defined primary or secondary outcomes. A total of 28 (73.7\%) studies included deceased donor recipients, eight (21.1\%) studies employed living donor recipients, and two studies combined both deceased and living donor recipients $(37,53)$. Only one study enrolled pediatric kidney recipients (age $\leq 18$ years) (37).

Five studies were excluded from the meta-analysis since they did not report the DGF rate after the study period. The remaining 33 studies included a total of $31,334 \mathrm{pa}-$ tients (15,809 in intervention and 15,525 in control groups). As shown in Figures 2 and 3, of the patients in the intervention groups, 13,655 patients received kidneys stored with machine perfusion rather than preserved in cold storage, 547 patients received grafts from donors who were prepared with an additional preventive agent, 470 patients experienced a type of conditioning technique before or during the surgery, 401 patients received innate inhibitors, 367 


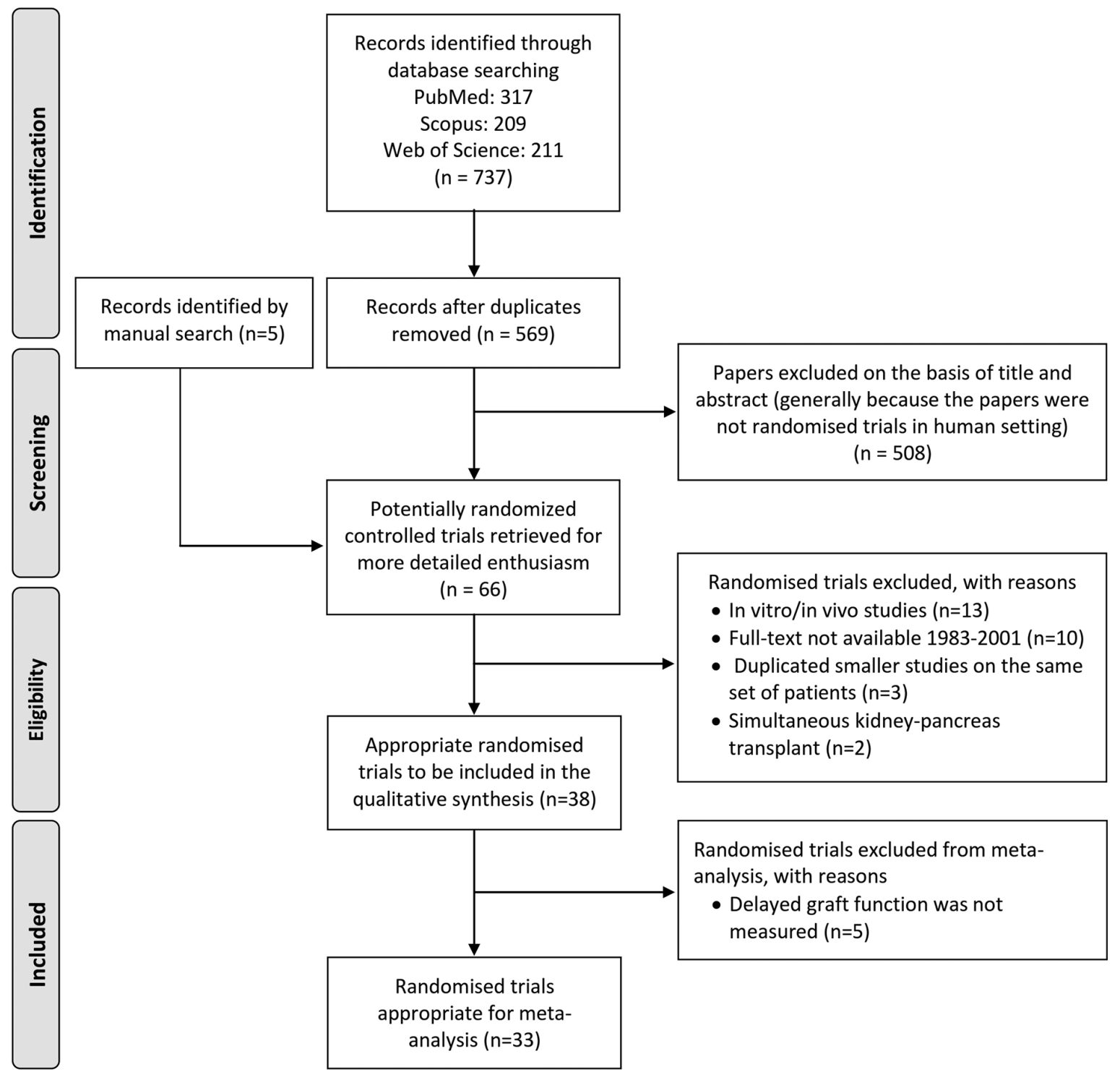

Figure 1. The PRISMA flow diagram of the study selection process

patients received antioxidants, 188 patients received CCBs, and 181 patients received anti-inflammatory agents.

\subsection{Risk of Bias and Quality Assessment}

The risks of selective reporting and attrition bias were deemed unclear for the majority of the studies ( $87 \%$ and $79 \%$, respectively). A total of 41 studies were associated with an unclear or high risk of selection bias due to the insufficient description of random sequence generation or allocation concealment. The performance and detection bias issues were fully explained in 50\% and 58\% of the studies, respectively. According to the AHRQ guidelines, about $8 \%$, $16 \%$, and $86 \%$ of the studies were considered methodologically to be of the good, fair, and poor level of quality, respectively (Table 2).

The inspection of the funnel plots represented remarkable asymmetry in four categories, suggesting a high level of publication bias. The innate inhibition, antioxidant, and conditioning categories were found to have a fair level of publication bias (Figure 4). 


$\begin{array}{lrr}\text { Study } & \begin{array}{c}\text { Innate Inhibitor } \\ \text { Events }\end{array} \\ \text { Salmela et al. } & 41 & 131 \\ \text { Goggings et al. } & 4 & 27 \\ \text { Osamagaber et al. } & 4 & 9 \\ \text { Stegall et al. } & 2 & 26 \\ \text { Moura et al. } & 62 & 97 \\ \text { Diuwe et al. } & 11 & 47 \\ \text { Kaabak et al. } & 0 & 29 \\ \text { Jordan et al. } & 15 & 35 \\ \text { Fixed Effect Model } & & \\ \text { Random Effects Model } & & 401 \\ \text { Heterogeneity: } I^{2}=58 \%, \tau^{2}=0.1164, p=0.02\end{array}$

Antioxidant Control

Study

Land et al.

Shoskes et al.

Sorbello et al.

Danilovic et al.

Cervantes et al.

Sahraei et al.

Nieuwenhuijs et al.

Fixed Effect Model

Random Effects Model

Heterogeneity: $I^{2}=33 \%, \tau^{2}=0.0706, p=0.18$ Events Total Events Total

\section{Control}

\section{ts Total}

$34 \quad 131$

$\begin{array}{rr}34 & 131 \\ 1 & 6\end{array}$

16

$\begin{array}{lr}21 & 51\end{array}$

$\begin{array}{rr}62 & 112 \\ 11 & 47\end{array}$

$\begin{array}{rr}11 & 47 \\ 3 & 28\end{array}$

$21 \quad 35$

441

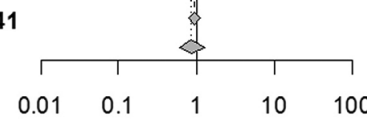

$0.01-0.1-1-10-100$
RR $\quad 95 \%-\mathrm{Cl}$ Weight Weight

$1.21[0.82 ; 1.77] \quad 22.3 \% \quad 21.9 \%$

$0.42[0.15 ; 1.16] \quad 6.7 \% \quad 8.8 \%$

$2.67[0.39 ; 18.42] \quad 0.8 \% \quad 3.1 \%$

$0.19[0.05 ; 0.74] \quad 9.3 \% \quad 5.6 \%$

$1.15[0.92 ; 1.44] \quad 37.7 \% \quad 26.3 \%$

$1.00 \quad[0.48 ; 2.08] \quad 7.2 \% \quad 13.3 \%$

$0.14[0.01 ; 2.55] \quad 2.3 \% \quad 1.5 \%$

$0.71[0.45 ; 1.14] \quad 13.7 \% \quad 19.6 \%$

$0.94[0.79 ; 1.12] 100.0 \%$ $0.86[0.60 ; 1.23]-100.0 \%$

- $100.0 \%$

\begin{tabular}{lrrrrr} 
& \multicolumn{2}{c}{$\begin{array}{c}\text { Anti-Inflammatory } \\
\text { Events }\end{array}$} & \multicolumn{2}{c}{ Contro } \\
Study & 0 & 20 & 0 & 20 \\
Othman et al. & 16 & 51 & 20 & 53 \\
Martinez et al. & 10 & 44 & 14 & 44 \\
Hafer et al. & 15 & 36 & 17 & 36 \\
Sureshkumar et al. & 3 & 30 & 1 & 30 \\
Kim et al. & & & & \\
Fixed Effect Model & & $\mathbf{1 8 1}$ & & 183 \\
Random Effects Model & & & & \\
Heterogeneity: $I^{2}=0 \%, \tau^{2}=0, p=0.68$ & &
\end{tabular}

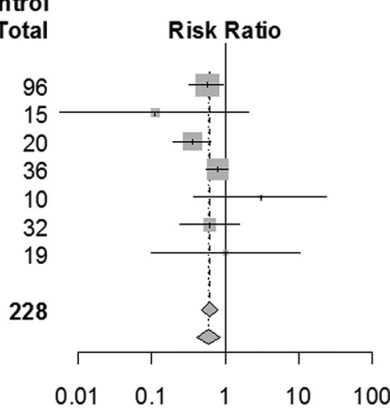

RR $\quad 95 \%-C l \quad \begin{aligned} & \text { Weight } \\ & \text { (Fixed) }\end{aligned} \begin{gathered}\text { Weight } \\ \text { (Random) }\end{gathered}$

$0.56[0.32 ; 0.95] \quad 33.5 \% \quad 24.5 \%$

$0.11[0.01 ; 2.13] \quad 3.7 \% \quad 1.5 \%$

$0.35[0.19 ; 0.63] \quad 19.6 \% \quad 22.3 \%$

$0.77[0.54 ; 1.09] \quad 30.6 \% \quad 34.7 \%$

$3.00[0.37 ; 24.17] \quad 1.1 \% \quad 3.0 \%$

$0.62[0.24 ; 1.59] \quad 9.9 \% \quad 11.7 \%$

$1.00[0.10 ; 10.34] \quad 1.5 \% \quad 2.4 \%$

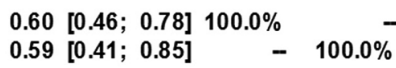

$$
\text { o }
$$
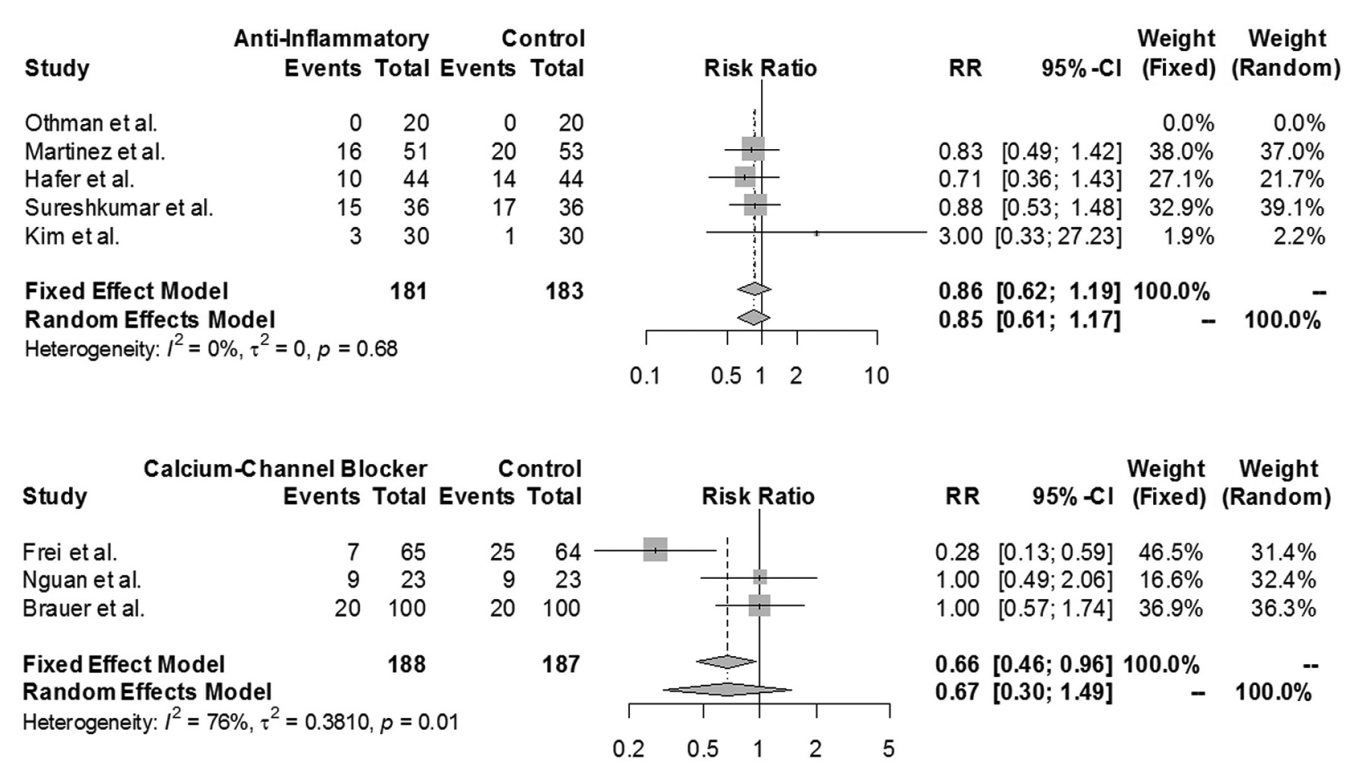

Figure 2. The risk ratio (RR) of the delayed graft function: Preventive agents versus control group

\subsection{Risk Ratio of Delayed Graft Function}

The fixed-effects meta-analysis suggested a trend toward machine perfusion in reducing the DGF rate in comparison with the traditional cold storage method $(\mathrm{RR}=$ $0.73 ; 95 \% \mathrm{CI}=0.7$ to $\left.0.76 ; \mathrm{I}^{2}=0 \% ; \mathrm{P}=0.81\right)$. Moreover, a statis- tically significant reduction in DGF was observed when an antioxidant agent was used $(\mathrm{RR}=0.6 ; 95 \% \mathrm{CI}=0.46$ to 0.78 ; $\mathrm{I}^{2}=33 \% ; \mathrm{P}=0.18$ ).

No significant effect was demonstrated for innate inhibitors $\left(\mathrm{RR}=0.86 ; 95 \% \mathrm{CI}=0.6\right.$ to $\left.1.23 ; \mathrm{I}^{2}=58 \% ; \mathrm{P}=0.02\right)$, 

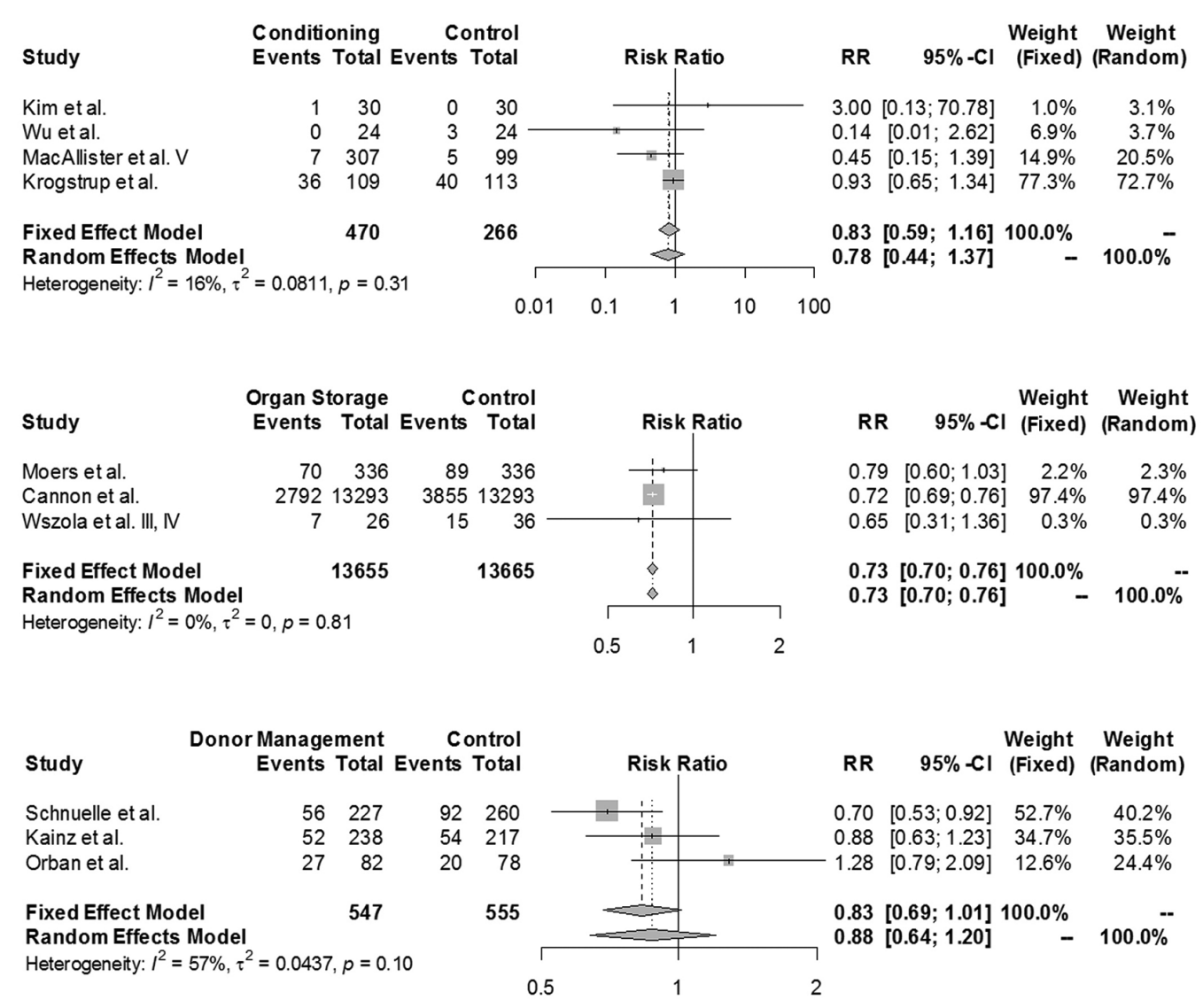

Figure 3. The risk ratio (RR) of the delayed graft function: Preventive techniques versus control group

anti-inflammatory agents $(\mathrm{RR}=0.86 ; 95 \% \mathrm{CI}$ : 0.62 to 1.19 ; $\mathrm{I} 2=0 \% ; \mathrm{P}=0.68), \mathrm{CCBs}\left(\mathrm{RR}=0.67 ; 95 \% \mathrm{CI}=0.3\right.$ to $1.49 ; \mathrm{I}^{2}=76 \%$; $\mathrm{P}=0.01)$, conditioning $\left(\mathrm{RR}=0.83 ; 95 \% \mathrm{CI}=0.59\right.$ to $1.16 ; \mathrm{I}^{2}$ $=16 \% ; \mathrm{P}=0.31)$, and donor management techniques $(\mathrm{RR}=$ $0.88 ; 95 \% \mathrm{CI}=0.64$ to $\left.1.2 ; \mathrm{I}^{2}=57 \% ; \mathrm{P}=0.1\right)$. The forest plots of the prevention categories are shown in Figures 2 and 3.

\subsection{Adverse Events}

Eighteen studies specified the occurrence of adverse reactions to prevention strategies. Of these, eight studies observed infection, mainly as a result of using innate inhibitors or CCBs (e.g., enlimomab, eculizumab, and thymoglobulin) $(27,30,31,33,34,37,44,50)$. The cytomegalovirus (CMV) and urinary tract infection (UTI) were the most frequent infections. In one study, the number of patients with CMV infection was significantly higher in the thymoglobulin group than in the control group (58.3\% vs. 17.1\%; $\mathrm{P}<0.001$ ) (34). There was also one incidence of Burkitt's lymphoma in the eculizumab group that resulted in the patient's death after deciding not to receive chemotherapy treatment (33). Four episodes of flulike infection were observed in pediatric patients receiving eculizumab (37).

Five studies reported circulatory adverse events, including hypotension and tachycardia $(25,41,48,49,54)$. Moreover, a total of 171 out of 307 patients developed paraesthesia or skin petechiae during remote ischemic preconditioning (RIPC) (46). A malfunctioning machine also caused a serious event due to uninterrupted inflation of the cuff during the conditioning process (47).

\section{Discussion}

Using the expanded criteria organs increases the risk of IRI, which diminishes the short- and long-term allograft function after kidney transplantation (57). Since the exact cellular mechanism of IRI is not fully understood, 

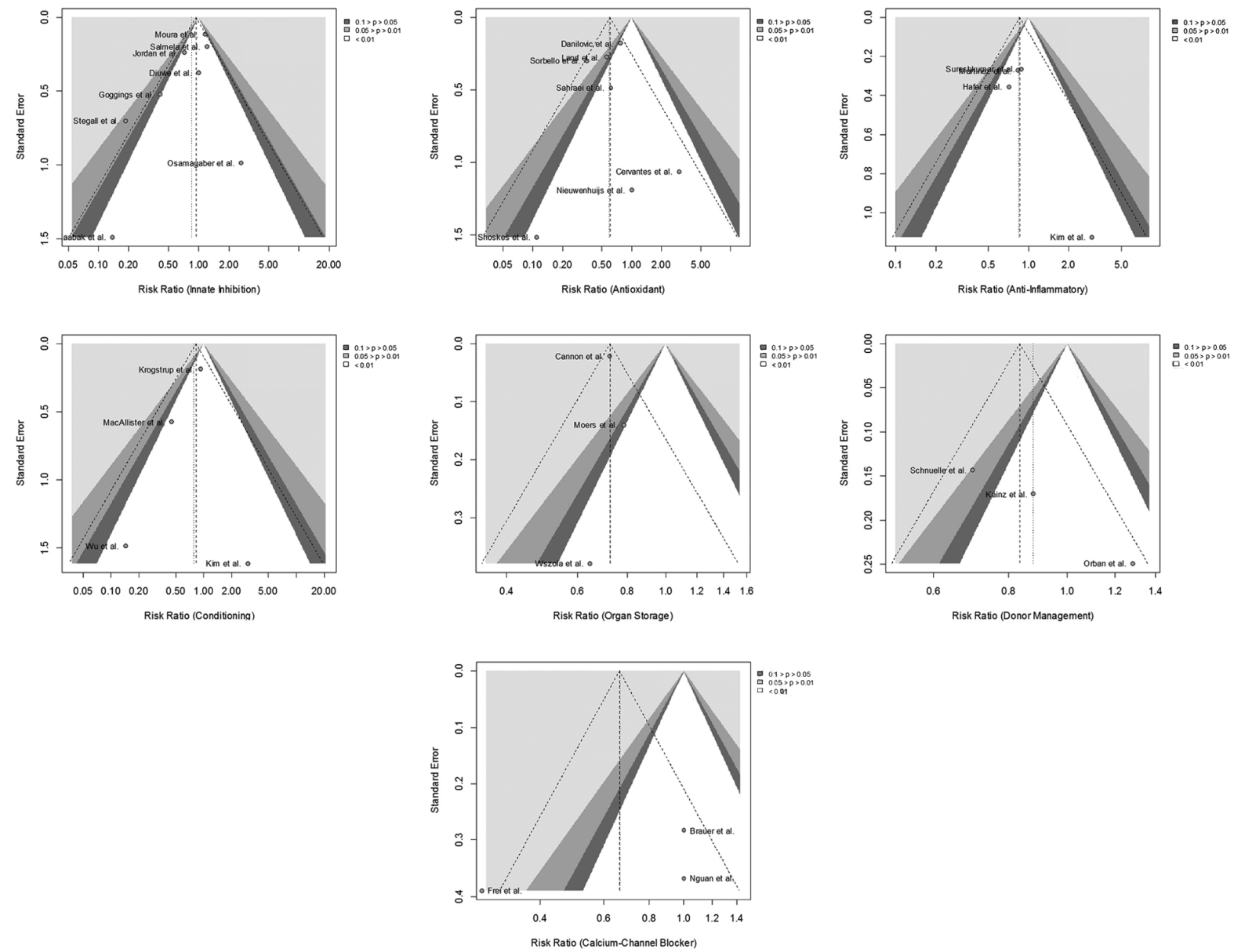

Figure 4. Funnel plots representing publication bias in each category of the preventive strategies

numerous studies have been performed focusing on different prevention hypotheses, which have been successfully tested in animal studies (58-61). However, our understanding of the utility and application of these strategies in the human setting is limited with no previously published comprehensive systematic review. Fixed and random-effects meta-analyses of the currently reported literature suggested that using the machine perfusion organ storage ( $\mathrm{RR}=0.73 ; 95 \% \mathrm{CI}=0.7$ to 0.76$)$ and administration of antioxidant agents $(\mathrm{RR}=0.6 ; 95 \% \mathrm{CI}=0.46$ to 0.78 ) significantly reduce the risk of DGF. The overall quality of evidence was low for the majority of the included studies (86\%) based on the AHRQ definitions.

The fixed-effects model of three homogenous studies in the organ storage category showed that although machine perfusion of donated kidneys is associated with longer cold ischemia time, it appears to offer remarkable protection against DGF (51-53). Two recent reviews confirmed the advantages of the hypothermic machine perfusion against IRI $(62,63)$. Moreover, it has been previously shown that the use of machine perfusion is associated with prolonged graft survival rate compared to the usual cold storage method (63).

Seven studies evaluating the effect of five antioxidants (i.e., rh-SOD, NAC, spironolactone, propofol, and curcumin) showed that the attenuation of oxidative stress improved sustained recovery of graft function. It has been previously shown that NAC has beneficial effects on the pathogenesis of acute renal disorders, including ischemic injuries $(64,65)$. Moreover, NAC preserves renal function during ischemic or reperfusion episodes by reducing renal interstitial inflammation. These effects are connected with increased renal glutathione levels, showing that NAC weakens renal oxidative stress (66). 
Most of the studies on the preventive effect of rh-SOD were performed in animal models in the 1990s (67). The hypothesis is that superoxide dismutase has beneficial effects on free radical-induced injuries as a powerful scavenger of superoxide anions. In addition, SOD catalyzes the dismutation of superoxide to hydrogen peroxide without affecting other parts of the molecular environment. This mechanism results in scavenging oxygen free radicals generated by hypoxia at the molecular level (68). Other antioxidants, including curcumin and spironolactone, have been evaluated focusing on the same mechanism. The advantageous effect of spironolactone on IRI has been previously confirmed in a rat model (69), but to the best of our knowledge, there are no similar studies on the preventive effect of curcumin in the transplantation area.

It is evident that the complex interplay of the innate and adaptive immune responses contributes to the pathogenesis of cell-mediated and antibody-mediated rejections (70). The following mechanisms and cells can contribute to immune response: cells (e.g., neutrophils, macrophages, dendritic cells or DCs, etc.), Toll-like receptors (TLRs), and the complement cascade.

It has been previously shown that the rabbit antithymocyte globulin (rATG) or thymoglobulin inhibits the function of DCs (71). A recent study in mice model has confirmed the powerful protective effect of T cell-specific NF$\kappa \mathrm{B}$ against IRI (72). Goggins et al. (31) and Requiao-Moura et al. (34) sought to study the effect of intraoperative administration of $3-6$ and one dose(s) of Thymoglobulin, respectively (1.5 and $1 \mathrm{mg} / \mathrm{kg}$ ). Contrary to the former study, Requiao-Moura et al. (34) showed that the incidence rate of DGF was similar in both groups $(\mathrm{P}=0.36)$. The important characteristic of this study was the prolonged mean cold ischemia time ( $24 \mathrm{~h}$ ) compared with the former study $(13 \mathrm{~h})$. It might be noted that the immunoprophylaxis effect of thymoglobulin might be suppressed in case of prolonged cold ischemia time. Moreover, the recombinant P-selectin glycoprotein ligand-Ig fusion protein (rPSGL-Ig) prevents granulocyte adhesion by binding the P- and Eselectin. Gaber et al. showed that YSPSL did not affect the DGF rate. However, treated patients had significantly lower creatinine levels (32). Further studies are needed to define the effect of YSPSL on early renal allograft function.

Several studies tried to inhibit the complement cascade as an important component of the innate immune response. The complement activation results in renal damage in two phases: first, during reperfusion after the cold ischemia time and second, after donor antigens are recognized by the adaptive immune system. Eculizumab is a long-acting, recombinant, humanized anti-C5 monoclonal antibody that might be useful as a prophylactic agent for the prevention of IRI. The infusion of eculizumab before graft reperfusion resulted in a lower DGF rate in the intervention group in two trials $(33,37)$. However, only one study reached a statistically significant level (33). Since it takes some hours to see the suppressive effect of eculizumab, it should be noted that pre-transplant infusion just before graft perfusion might reduce its effectiveness. Moreover, the beneficial effect of C1-inhibitor (C1INH) also has been mostly observed in rodents (73). The only trial included in our review confirmed its preventive effect by blocking the classical or lectin pathway of the complement cascade (36).

Previous studies in animal models have shown encouraging results on the protective effect of EPO against IRI (74, 75). The hypothesis is that when EPO receptors are activated, EPO leads to a protective effect on proximal tubular epithelial cells. In contrast to the promising findings of animal studies, the included trials in human settings showed a significant reduction neither in the incidence rate of DGF nor in graft function. However, since confidence intervals are rather large, the possibility of the significant effect of EPO in larger populations cannot be definitely excluded.

Ischemia causes the intracellular accumulation of $\mathrm{Na}^{+}$ ions and $\mathrm{Ca}^{+}$levels. This calcium overload results in the activation of calcium-related proteases. Calpains are one of these proteases that remains inactive due to acidosis environment during the ischemic phase. After $\mathrm{pH}$ normalization at reperfusion, calpains cause cell structure impairment and consequently cell death. The $\mathrm{Ca}^{+}$accumulation also causes the generation of reactive oxygen species (ROS). Calcium-channel blockers are used to slow down this harmful process. However, currently published articles did not show the protective effect of verapamil (organ reperfusion) and prostaglandin (infusion) against IRI (49, 50). In contrast, Frei et al. (48) showed that the intraoperative infusion of diltiazem in addition to diltiazem pretreatment (organ reperfusion in $500 \mathrm{ml}$ Euro-Collins with diltiazem) significantly decreased the DGF rate.

The protective effect of remote ischemic conditioning (RIC) has been shown in a variety of clinical settings (e.g. heart and liver) (76). Four studies performed 3 - 4 cycles of 5-min repetitive ischemia and reperfusion by clamping either upper limb or thigh before graft reperfusion (4447). None of the studies found significant differences in the DGF rate between the control and intervention groups. However, the secondary analysis of the large REPAIR (REmote preconditioning for protection against ischemia- 
reperfusion in renal transplantation) study found a significant improvement in eGFR $(\mathrm{P}=0.022)(46)$. Considering the low cost of delivery, no potential harms, and the chance of improving graft function, future investigations are required to define the role of RIC in both deceased and living donor transplantation areas.

Another important factor to reduce the risk of IRI is the optimal management of deceased donors. A published article in 2015 showed that donor pretreatment with NAC did not reduce the DGF rate, as well as short-term graft function assessed by serum creatinine, eGFR, and urine output (56). Moreover, Kainz et al. (55) did not observe a significant improvement in graft function after administration of $1,000 \mathrm{mg}$ corticosteroids to donors at least three hours before organ harvesting. In contrast, a randomized, multi-center trial in Europe showed the salutary effect of donor pretreatment with low-dose dopamine on graft performance (54).

\subsection{Limitations and Strengths}

The following limitations should be acknowledged both at qualitative and quantitative levels. First, a high degree of heterogeneity in innate inhibitor, $\mathrm{CCB}$, and donor management groups prevented us to fully assess the effect of these strategies on the DGF rate. This heterogeneity could possibly be due to high variation among included studies concerning the ethnicity of participants, administration time of the preventive agent (e.g., before, during, or after transplantation), mode of administration (e.g., infusion, oral, etc.), the dosage of the agents, etc. However, we could not perform a meta-regression analysis due to the paucity of the relevant data. Second, we extracted the DGF rates based on the definitions used in the trials. As suggested by a previously published systematic review, this heterogeneity in DGF definitions hinders the evolution of both clinical and research practices for the diagnosis and treatment of IRI (8). Third, our qualitative synthesis showed that the published trials were mostly of fair or poor quality level. Fourth, since most of the included trials had small-sized populations, the results represented small effect estimates, which may affect the generalizability of the findings.

Despite the limitations, our review included randomized controlled trials from 18 countries, which included diverse practice settings from different developing and developed countries. Moreover, a fixed-effects meta-analysis was carried out in four categories, which showed the acceptable level of homogeneity within the included trials in these groups.

\section{Conclusions}

Considering the evidence on the reduced DGF rate by the machine perfusion storage technique, it might be proposed to substantially expand the use of machine perfusion beyond current levels. In contrast, high adverse events of innate inhibitors in addition to their low effectiveness highlight the need for large-scale randomized controlled trials to be conducted in a clinically useful manner. Moreover, using the standard definition of DGF will help future researchers to integrate the results and provide practical guidelines.

\section{Acknowledgments}

The authors would like to thank the corresponding authors who emailed us the supplementary files of their studies.

\section{Footnotes}

Authors' Contribution: All authors contributed to the study conception and design. Fariba Tohidinezhad and Mahmoud Tavakkoli performed the title and abstract screening in addition to data acquisition from the included full-texts. Saba Vakili performed the manual search. Fariba Tohidinezhad and Saeid Eslami performed statistical analysis. Mohsen Aliakbarian and Mahmoud Tavakkoli interpreted the results. Fariba Tohidinezhad and Mohsen Aliakbarian drafted the manuscript and all the authors made critical revision and final approval of the manuscript.

Conflict of Interests: No conflict of interest in this study is reported.

Funding/Support: The authors received no specific funding for this work.

\section{References}

1. Ausania F, White SA, Pocock P, Manas DM. Kidney damage during organ recovery in donation after circulatory death donors: data from UK National Transplant Database. Am J Transplant. 2012;12(4):932-6. doi: 10.1111/j.1600-6143.2011.03882.x. [PubMed: 22225959].

2. Ledinh H, Weekers L, Bonvoisin C, Krzesinski JM, Monard J, de Roover A, et al. Results of kidney transplantation from controlled donors after cardio-circulatory death: A single center experience. Transpl Int. 2012;25(2):201-9. doi: 10.1111/j.1432-2277.2011.01402.x. [PubMed: 22220676].

3. Brook NR, Waller JR, Nicholson ML. Nonheart-beating kidney donation: Current practice and future developments. Kidney Int. 2003;63(4):1516-29. doi: 10.1046/j.1523-1755.2003.00854.x. [PubMed: $12631369]$. 
4. Munshi R, Hsu C, Himmelfarb J. Advances in understanding ischemic acute kidney injury. BMC Med. 2011;9:11. doi: 10.1186/1741-7015-9-11. [PubMed: 21288330]. [PubMed Central: PMC3038966].

5. Bonventre JV, Yang L. Cellular pathophysiology of ischemic acute kidney injury. J Clin Invest. 2011;121(11):4210-21. doi: 10.1172/JCI45161. [PubMed: 22045571]. [PubMed Central: PMC3204829].

6. Quiroga I, McShane P, Koo DD, Gray D, Friend PJ, Fuggle S, et al. Major effects of delayed graft function and cold ischaemia time on renal allograft survival. Nephrol Dial Transplant. 2006;21(6):1689-96. doi: 10.1093/ndt/gflo42. [PubMed: 16490743].

7. Ponticelli C. Ischaemia-reperfusion injury: A major protagonist in kidney transplantation. Nephrol Dial Transplant. 2014;29(6):1134-40. doi:10.1093/ndt/gft488. [PubMed: 24335382].

8. Yarlagadda SG, Coca SG, Garg AX, Doshi M, Poggio E, Marcus RJ, et al. Marked variation in the definition and diagnosis of delayed graft function: a systematic review. Nephrol Dial Transplant. 2008;23(9):2995-3003. doi: 10.1093/ndt/gfn158. [PubMed: 18408075]. [PubMed Central: PMC2727302].

9. Sanfilippo F, Vaughn WK, Spees EK, Lucas BA. The detrimental effects of delayed graft function in cadaver donor renal transplantation. Transplantation. 1984;38(6):643-8. doi: 10.1097/00007890-19841200000019. [PubMed: 6390827].

10. Diepenhorst GM, van Gulik TM, Hack CE. Complement-mediated ischemia-reperfusion injury: Lessons learned from animal and clinical studies. Ann Surg. 2009;249(6):889-99. doi: 10.1097/SLA.ob013e3181a38f45. [PubMed: 19474697].

11. Liberati A, Altman DG, Tetzlaff J, Mulrow C, Gotzsche PC, Ioannidis JP, et al. The PRISMA statement for reporting systematic reviews and meta-analyses of studies that evaluate healthcare interventions: Explanation and elaboration. BMJ. 2009;339:b2700. doi: 10.1136/bmj.b2700. [PubMed: 19622552]. [PubMed Central: PMC2714672].

12. Sideri S, Papageorgiou SN, Eliades T. Registration in the international prospective register of systematic reviews (PROSPERO) of systematic review protocols was associated with increased review quality. J Clin Epidemiol. 2018;100:103-10. doi: 10.1016/j.jclinepi.2018.01.003. [PubMed: 29339215].

13. Higgins JP, Altman DG, Gotzsche PC, Juni P, Moher D, Oxman AD, et al. The Cochrane Collaboration's tool for assessing risk of bias in randomised trials. BMJ. 2011;343:d5928. doi: 10.1136/bmj.d5928. [PubMed: 22008217]. [PubMed Central: PMC3196245].

14. McPheeters MLKS, Peterson NB. Closing the quality gap: Revisiting the state of the science (vol. 3: quality improvement interventions to address health disparities). US: Agency for Healthcare Research and Quality; 2012.

15. Salvadori M, Rosso G, Bertoni E. Update on ischemia-reperfusion injury in kidney transplantation: Pathogenesis and treatment. World J Transplant. 2015;5(2):52-67. doi: 10.5500/wjt.v5.i2.52. [PubMed: 26131407]. [PubMed Central: PMC4478600].

16. Higgins JPT, Green S. Cochrane handbook for systematic reviews of interventions version 5.1. 0 [updated March 2011]. The cochrane collaboration, 2011. Accessed August. 2011. Available from: https://training.cochrane. org/handbook.

17. Higgins JP, Thompson SG. Quantifying heterogeneity in a metaanalysis. Stat Med.2002;21(11):1539-58. doi: 10.1002/sim.1186. [PubMed: 12111919].

18. Sweeting MJ, Sutton AJ, Lambert PC. What to add to nothing? Use and avoidance of continuity corrections in meta-analysis of sparse data. Stat Med.2004;23(9):1351-75. doi:10.1002/sim.1761. [PubMed:15116347].

19. Pollak R, Andrisevic JH, Maddux MS, Gruber SA, Paller MS. A randomized double-blind trial of the use of human recombinant superoxide dismutase in renal transplantation. Transplantation. 1993;55(1):57-60. doi: 10.1097/00007890-199301000-00011. [PubMed: 8420065].
20. Rabl H, Khoschsorur G, Colombo T, Petritsch P, Rauchenwald M Koltringer $\mathrm{P}$, et al. A multivitamin infusion prevents lipid peroxidation and improves transplantation performance. Kidney Int 1993;43(4):912-7. doi: 10.1038/ki.1993.128. [PubMed: 8479129].

21. Land W, Schneeberger H, Schleibner S, Illner WD, Abendroth D, Rutili $G$, et al. The beneficial effect of human recombinant superoxide dismutase on acute and chronic rejection events in recipients of cadaveric renal transplants. Transplantation. 1994;57(2):211-7. doi: 10.1097/00007890-199401001-00010. [PubMed: 8310510].

22. Fontana I, Germi MR, Beatini M, Fontana S, Bertocchi M, Porcile E, et al. Dopamine "renal dose" versus fenoldopam mesylate to prevent ischemia-reperfusion injury in renal transplantation. Transplant Proc. 2005;37(6):2474-5. doi: 10.1016/j.transproceed.2005.06.102. [PubMed: $16182714]$.

23. Shoskes D, Lapierre C, Cruz-Corerra M, Muruve N, Rosario R, Fromkin $\mathrm{B}$, et al. Beneficial effects of the bioflavonoids curcumin and quercetin on early function in cadaveric renal transplantation: A randomized placebo controlled trial. Transplantation. 2005;80(11):1556-9. doi: 10.1097/01.tp.0000183290.64309.21. [PubMed: 16371925].

24. Basu S, Meisert I, Eggensperger E, Krieger E, Krenn CG. Time course and attenuation of ischaemia-reperfusion induced oxidative injury by propofol in human renal transplantation. Redox Rep. 2007;12(4):195-202. doi: 10.1179/135100007X200281. [PubMed: 17705990].

25. Sorbello M, Morello G, Parrinello L, Molino C, Rinzivillo D, Pappalardo $\mathrm{R}$, et al. Effect of $\mathrm{N}$-acetyl-cysteine (NAC) added to fenoldopam or dopamine on end-tidal carbon dioxide and mean arterial pressure at time of renal artery declamping during cadaveric kidney transplantation. Transplant Proc. 2010;42(4):1056-60. doi 10.1016/j.transproceed.2010.03.072. [PubMed: 20534223].

26. Danilovic A, Lucon AM, Srougi M, Shimizu MH, Ianhez LE, Nahas WC, et al. Protective effect of N-acetylcysteine on early outcomes of deceased renal transplantation. Transplant Proc. 2011;43(5):1443-9. doi: 10.1016/j.transproceed.2011.02.020. [PubMed: 21693215].

27. Ojeda-Cervantes M, Barrera-Chimal J, Alberu J, Perez-Villalva R, Morales-Buenrostro LE, Bobadilla NA. Mineralocorticoid receptor blockade reduced oxidative stress in renal transplant recipients: A double-blind, randomized pilot study. Am J Nephrol. 2013;37(5):481-90. doi: 10.1159/000350539. [PubMed: 23635604].

28. Sahraei Z, Salamzadeh J, Nafar M. Effect of N-acetyl cysteine and vitamin $\mathrm{C}$ on kidney allograft function biomarkers interleukin-18 and neutrophil gelatinase-associated lipocalin. Iran J Kidney Dis. 2015;9(1):56-62. [PubMed: 25599738].

29. Nieuwenhuijs-Moeke GJ, Nieuwenhuijs VB, Seelen MAJ, Berger SP, van den Heuvel MC, Burgerhof JGM, et al. Propofol-based anaesthesia versus sevoflurane-based anaesthesia for living donor kidney transplantation: results of the VAPOR-1 randomized controlled trial.BrJAnaesth.2017;118(5):720-32. doi:10.1093/bja/aex057.[PubMed: 28510740].

30. Salmela K, Wramner L, Ekberg H, Hauser I, Bentdal O, Lins LE, et al. A randomized multicenter trial of the anti-ICAM-1 monoclonal antibody (enlimomab) for the prevention of acute rejection and delayed onset of graft function in cadaveric renal transplantation: A report of the European Anti-ICAM-1 renal transplant study group. Transplantation. 1999;67(5):729-36. doi: 10.1097/00007890-19990315000015. [PubMed: 10096530].

31. Goggins WC, Pascual MA, Powelson JA, Magee C, Tolkoff-Rubin N, Farrell $\mathrm{ML}$, et al. A prospective, randomized, clinical trial of intraoperative versus postoperative thymoglobulin in adult cadaveric renal transplant recipients. Transplantation. 2003;76(5):798-802. doi 10.1097/01.TP.0000081042.67285.91. [PubMed: 14501856].

32. Gaber AO, Mulgaonkar S, Kahan BD, Woodle ES, Alloway R, Bajjoka I, 
et al. YSPSL (rPSGL-Ig) for improvement of early renal allograft function: Adouble-blind, placebo-controlled, multi-center Phase IIa study. Clin Transplant. 2011;25(4):523-33. doi: 10.1111/j.1399-0012.2010.01295.x. [PubMed: 20573162].

33. Stegall MD, Diwan T, Raghavaiah S, Cornell LD, Burns J, Dean PG, et al. Terminal complement inhibition decreases antibody-mediated rejection in sensitized renal transplant recipients. Am J Transplant. 2011;11(11):2405-13. doi: 10.1111/j.1600-6143.2011.03757.x. [PubMed: 21942930].

34. Requiao-Moura LR, Ferraz E, Matos AC, Tonato EJ, Ozaki KS, Durao MS, et al. Comparison of long-term effect of thymoglobulin treatment in patients with a high risk of delayed graft function. Transplant Proc. 2012;44(8):2428-33. doi: 10.1016/j.transproceed.2012.07.013. [PubMed: 23026612].

35. Diuwe P, Domagala P, Durlik M, Trzebicki J, Chmura A, Kwiatkowski A. The effect of the use of a TNF-alpha inhibitor in hypothermic machine perfusion on kidney function after transplantation. Contemp Clin Trials. 2017;59:44-50. doi:10.1016/j.cct.2017.05.013. [PubMed: 28571996].

36. Jordan SC, Choi J, Aubert O, Haas M, Loupy A, Huang E, et al. A phase $\mathrm{I} / \mathrm{II}$, double-blind, placebo-controlled study assessing safety and efficacy of $\mathrm{C} 1$ esterase inhibitor for prevention of delayed graft function in deceased donor kidney transplant recipients. Am J Transplant. 2018;18(12):2955-64. doi: 10.1111/ajt.14767. [PubMed: 29637714].

37. Kaabak M, Babenko N, Shapiro R, Zokoyev A, Dymova O, Kim E. A prospective randomized, controlled trial of eculizumab to prevent ischemia-reperfusion injury in pediatric kidney transplantation. Pediatr Transplant. 2018;22(2). doi: 10.1111/petr.13129. [PubMed: 29377474].

38. Othman MM, Ismael AZ, Hammouda GE. The impact of timing of maximal crystalloid hydration on early graft function during kidney transplantation. Anesth Analg. 2010;110(5):1440-6. doi: 10.1213/ANE.ob013e3181d82ca8. [PubMed: 20418304].

39. Martinez F, Kamar N, Pallet N, Lang P, Durrbach A, Lebranchu Y, et al. High dose epoetin beta in the first weeks following renal transplantation and delayed graft function: Results of the Neo-PDGF study. Am J Transplant. 2010;10(7):1695-700. doi: 10.1111/j.1600-6143.2010.03142.x. [PubMed: 20642691].

40. Hafer C, Becker T, Kielstein JT, Bahlmann E, Schwarz A, Grinzoff N, et al. High-dose erythropoietin has no effect on short- or long-term graft function following deceased donor kidney transplantation. Kidney Int. 2012;81(3):314-20. doi: 10.1038/ki.2011.349. [PubMed: 22012130].

41. Sureshkumar KK, Hussain SM, Ko TY, Thai NL, Marcus RJ. Effect of high-dose erythropoietin on graft function after kidney transplantation: A randomized, double-blind clinical trial. Clin J Am Soc Nephrol. 2012;7(9):1498-506. doi: 10.2215/CJN.01360212. [PubMed: 22745272]. [PubMed Central: PMC3430945].

42. Kim SY, Huh KH, Lee JR, Kim SH, Jeong SH, Choi YS. Comparison of the effects of normal saline versus Plasmalyte on acid-base balance during living donor kidney transplantation using the Stewart and base excess methods. Transplant Proc. 2013;45(6):2191-6. doi: 10.1016/j.transproceed.2013.02.124. [PubMed: 23953528].

43. Hatem A, Ahmed S, Asam M, Laura EH, Aimun A. Effect of long-term, low-dose aspirin therapy on renal graft function. Exp Clin Transplant. 2017;15(4):400-4. doi: 10.6002/ect.2016.0139. [PubMed: 28004997].

44. Kim WH, Lee JH, Kim GS, Sim HY, Kim SJ. The effect of remote ischemic postconditioning on graft function in patients undergoing living donor kidney transplantation. Transplantation. 2014;98(5):52936. doi: 10.1097/TP.0000000000000098. [PubMed: 24770616].

45. Wu J, Feng X, Huang $H$, Shou Z, Zhang X, Wang R, et al. Remote ischemic conditioning enhanced the early recovery of renal function in recipients after kidney transplantation: A randomized controlled trial.J Surg Res. 2014;188(1):303-8. doi: 10.1016/j.jss.2013.06.058. [PubMed: 24556231].

46. MacAllister R, Clayton T, Knight R, Robertson S, Nicholas J, Mot- wani $\mathrm{M}$, et al. REmote preconditioning for protection against ischaemiareperfusion in renal transplantation (REPAIR): A multicentre, multinational, double-blind, factorial designed randomised controlled trial. UK: Southampton; 2015. eng. doi: 10.3310/eme02030.

47. Krogstrup NV, Oltean M, Nieuwenhuijs-Moeke GJ, Dor FJ, Moldrup $\mathrm{U}$, Krag SP, et al. Remote ischemic conditioning on recipients of deceased renal transplants does not improve early graft function: a multicenter randomized, controlled clinical trial. Am J Transplant. 2017;17(4):1042-9. doi: 10.1111/ajt.14075. [PubMed: 27696662].

48. Frei U, Harms A, Bakovic-Alt R, Pichlmayr R, Koch KM. Calcium channel blockers for kidney protection.JCardiovasc Pharmacol.1990;16:S115. doi:10.1097/00005344-199006166-00004.

49. Nguan CY, Sener A, Karnik V, Caumartin Y, House AA, McAlister VC, et al. Perfusion of renal allografts with verapamil improves graft function. Transplantation. 2008;86(10):1463-7. doi: 10.1097/TP.ob013e3181889979. [PubMed: 19034018].

50. Brauer RB, Marx T, Ulm K, Stangl MJ. Effect of perioperative administration of a drug regimen on the primary function of human renal allografts. Transplant Proc. 2010;42(5):1523-5. doi: 10.1016/j.transproceed.2010.01.057. [PubMed: 20620467].

51. Moers C, Smits JM, Maathuis MH, Treckmann J, van Gelder F, Napieralski BP, et al. Machine perfusion or cold storage in deceased-donor kidney transplantation. N Engl J Med. 2009;360(1):7-19. doi: 10.1056/NEJMoa0802289. [PubMed: 19118301].

52. Cannon RM, Brock GN, Garrison RN, Smith JW, Marvin MR, Franklin GA. To pump or not to pump: A comparison of machine perfusion vs cold storage for deceased donor kidney transplantation. J Am Coll Surg. 2013;216(4):625-33. discussion 633-4. doi: 10.1016/j.jamcollsurg.2012.12.025. [PubMed: 23521942].

53. Wszola M, Kwiatkowski A, Domagala P, Wirkowska A, Bieniasz M, Diuwe $P$, et al. Preservation of kidneys by machine perfusion influences gene expression and may limit ischemia/reperfusion injury. Prog Transplant. 2014;24(1):19-26. doi: 10.7182/pit2014384. [PubMed: 24598561].

54. Schnuelle P, Gottmann U, Hoeger S, Boesebeck D, Lauchart W, Weiss C, et al. Effects of donor pretreatment with dopamine on graft function after kidney transplantation: A randomized controlled trial. JAMA. 2009;302(10):1067-75. doi: 10.1001/jama.2009.1310. [PubMed: 19738091].

55. Kainz A, Wilflingseder J, Mitterbauer C, Haller M, Burghuber C, Perco $\mathrm{P}$, et al. Steroid pretreatment of organ donors to prevent postischemic renal allograft failure: A randomized, controlled trial. Ann Intern Med. 2010;153(4):222-30. doi: 10.7326/0003-4819-153-4-20100817000003. [PubMed: 20713790].

56. Orban JC, Quintard H, Cassuto E, Jambou P, Samat-Long C, Ichai C. Effect of N-acetylcysteine pretreatment of deceased organ donors on renal allograft function: A randomized controlled trial. Transplantation. 2015;99(4):746-53. doi: 10.1097/TP.0000000000000395. [PubMed: 25250647]. [PubMed Central: PMC4376274].

57. Zhao H, Alam A, Soo AP, George AJT, Ma D. Ischemia-reperfusion injury reduces long term renal graft survival: Mechanism and beyond. EBioMedicine. 2018;28:31-42. doi: 10.1016/j.ebiom.2018.01.025. [PubMed: 29398595]. [PubMed Central: PMC5835570].

58. Yu ZX, Qi S, Lasaro MA, Bouchard K, Dow C, Moore K, et al. Targeting complement pathways during cold ischemia and reperfusion prevents delayed graft function. Am J Transplant. 2016;16(9):2589-97. doi: 10.1111/ajt.13797. [PubMed: 27003920].

59. Gong H, Sun J, Xue W, Tian P, Ding X, Yan H, et al. Protective effect of truncated $\mathrm{Na}+/ \mathrm{K}+$-ATPase beta on ischemia/reperfusion-induced renal injury in rats. Exp Biol Med (Maywood). 2014;239(6):677-85. doi: 10.1177/1535370213517613. [PubMed: 24737734].

60. van Rijt WG, Nieuwenhuijs-Moeke GJ, van Goor H, Jespersen B, Ot- 
tens PJ, Ploeg RJ, et al. ARA290, a non-erythropoietic EPO derivative, attenuates renal ischemia/reperfusion injury. J Transl Med. 2013;11:9. doi: 10.1186/1479-5876-11-9. [PubMed: 23302512]. [PubMed Central: PMC3567997].

61. Chen KY, Zhang YN, Diao YG, Zhou J, Zhang TZ. Symbol dexmedetomidine inhibits renal ischemia/reperfusion-induced inflammatory reaction. J Clin Rehabil Tissue Engin Res. 2013;17(53):9189-95.

62. Bon D, Delpech PO, Chatauret N, Hauet T, Badet L, Barrou B. Does machine perfusion decrease ischemia reperfusion injury? Prog Urol. 2014;24 Suppl 1:S44-50. doi: 10.1016/S1166-7087(14)70063-6. [PubMed: 24950933].

63. Barrou B, Chatauret N, Hauet T, Thuret R, Kleinclauss F, Timsit MO, et al. [Ischemia-reperfusion. Preservation solution and hypothermic machine perfusion]. Prog Urol. 2016;26(15):964-76. French. doi: 10.1016/j.purol.2016.08.007. [PubMed: 27693279].

64. Shimizu MH, Danilovic A, Andrade L, Volpini RA, Liborio AB, Sanches $\mathrm{TR}$, et al. N-acetylcysteine protects against renal injury following bilateral ureteral obstruction. Nephrol Dial Transplant. 2008;23(10):306773. doi: 10.1093/ndt/gfn237. [PubMed: 18469310]. [PubMed Central: PMC2542407].

65. de Araujo M, Andrade L, Coimbra TM, Rodrigues AJ, Seguro AC. Magnesium supplementation combined with N-acetylcysteine protects against postischemic acute renal failure. I Am Soc Nephrol. 2005;16(11):3339-49. doi: 10.1681/ASN.2004100832. [PubMed: 16177005].

66. Nitescu N, Ricksten SE, Marcussen N, Haraldsson B, Nilsson U, Basu $\mathrm{S}$, et al. $\mathrm{N}$-acetylcysteine attenuates kidney injury in rats subjected to renal ischaemia-reperfusion. Nephrol Dial Transplant. 2006;21(5):12407. doi: 10.1093/ndt/gfk032. [PubMed:16390850].

67. Flohe L. Superoxide dismutase for therapeutic use: Clinical experience, dead ends and hopes. Mol Cell Biochem. 1988;84(2):123-31. doi: 10.1007/bf00421046. [PubMed: 3068519].

68. Zweier JL, Talukder MA. The role of oxidants and free radicals in reperfusion injury. Cardiovasc Res. 2006;70(2):181-90. doi: 10.1016/j.cardiores.2006.02.025. [PubMed: 16580655].
69. Sanchez-Pozos K, Barrera-Chimal J, Garzon-Muvdi J, Perez-Villalva R, Rodriguez-Romo R, Cruz C, et al. Recovery from ischemic acute kidney injury by spironolactone administration. Nephrol Dial Transplant 2012;27(8):3160-9. doi: 10.1093/ndt/gfs014. [PubMed: 22516623].

70. Fuquay R, Renner B, Kulik L, McCullough JW, Amura C, Strassheim D, et al. Renal ischemia-reperfusion injury amplifies the humoral immune response. J Am Soc Nephrol. 2013;24(7):1063-72. doi: 10.1681/ASN.2012060560. [PubMed: 23641055]. [PubMed Central: PMC3699821].

71. Naujokat C, Berges C, Fuchs D, Sadeghi M, Opelz G, Daniel V. Antithymocyte globulins suppress dendritic cell function by multiple mechanisms. Transplantation. 2007;83(4):485-97. doi: 10.1097/01.tp.0000251975.81281.22. [PubMed:17318082].

72. Xue C, Liu Y, Li C, Li Y, Yang T, Xie L, et al. Powerful protection against renal ischemia reperfusion injury by $T$ cell-specific NF-kappaB inhibition. Transplantation. 2014;97(4):391-6. doi: 10.1097/01.TP.0000438622.89310.95. [PubMed: 24398854].

73. Castellano G, Melchiorre R, Loverre A, Ditonno P, Montinaro V, Rossini $\mathrm{M}$, et al. Therapeutic targeting of classical and lectin pathways of complement protects from ischemia-reperfusion-induced renal damage. Am J Pathol. 2010;176(4):1648-59. doi: 10.2353/ajpath.2010.090276. [PubMed: 20150432]. [PubMed Central: PMC2843457].

74. Vesey DA, Cheung C, Pat B, Endre Z, Gobe G, Johnson DW. Erythropoietin protects against ischaemic acute renal injury. Nephrol Dial Transplant.2004;19(2):348-55. doi:10.1093/ndt/gfg547.[PubMed:14736958].

75. Sharples EJ, Patel N, Brown P, Stewart K, Mota-Philipe H, Sheaff M, et al. Erythropoietin protects the kidney against the injury and dysfunction caused by ischemia-reperfusion. J Am Soc Nephrol. 2004;15(8):2115-24. doi: 10.1097/01.ASN.0000135059.67385.5D. [PubMed: 15284297].

76. Heusch G, Botker HE, Przyklenk K, Redington A, Yellon D. Remote ischemic conditioning. J Am Coll Cardiol. 2015;65(2):177-95. doi: 10.1016/j.jacc.2014.10.031. [PubMed: 25593060]. [PubMed Central: PMC4297315]. 


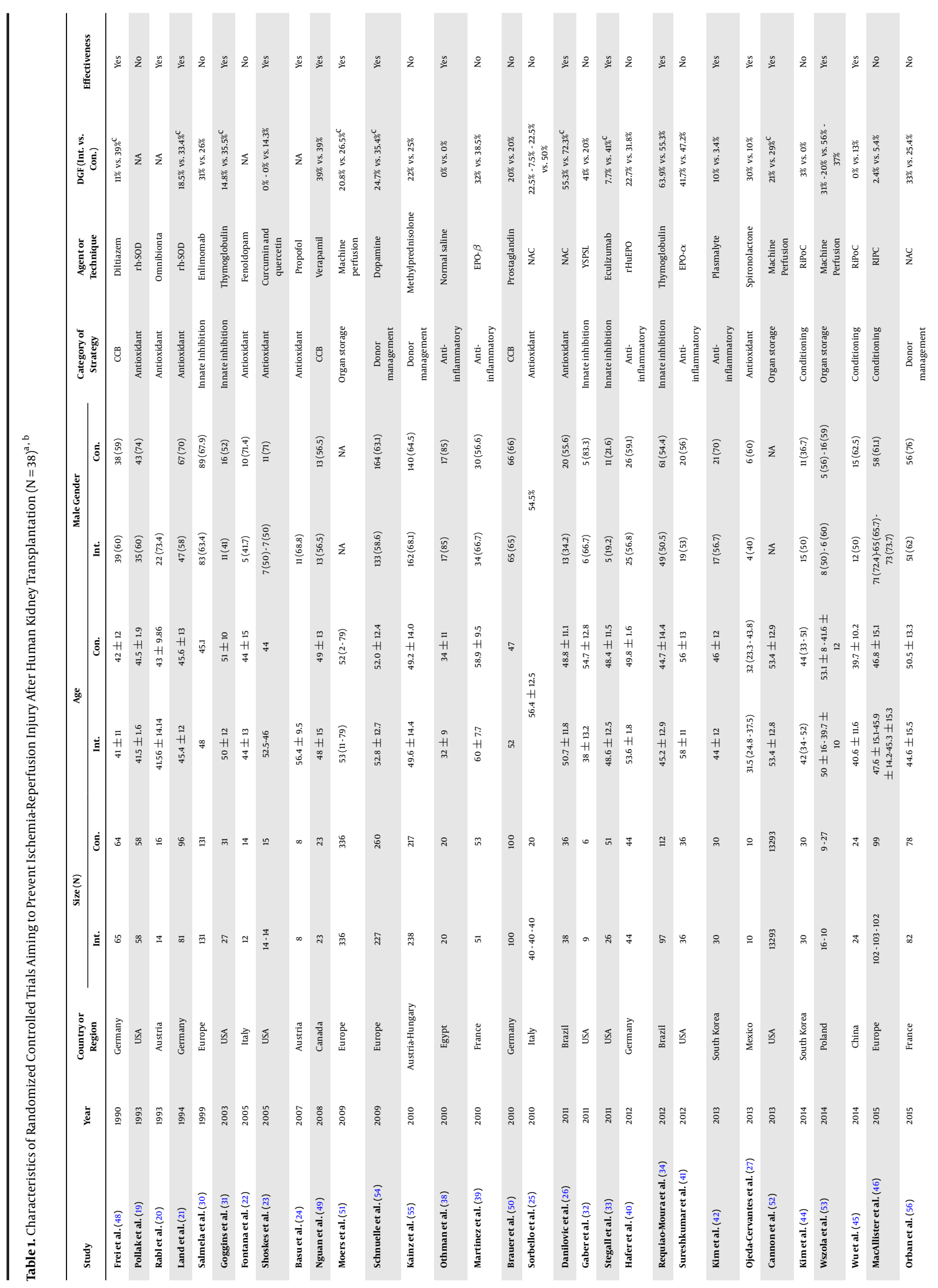




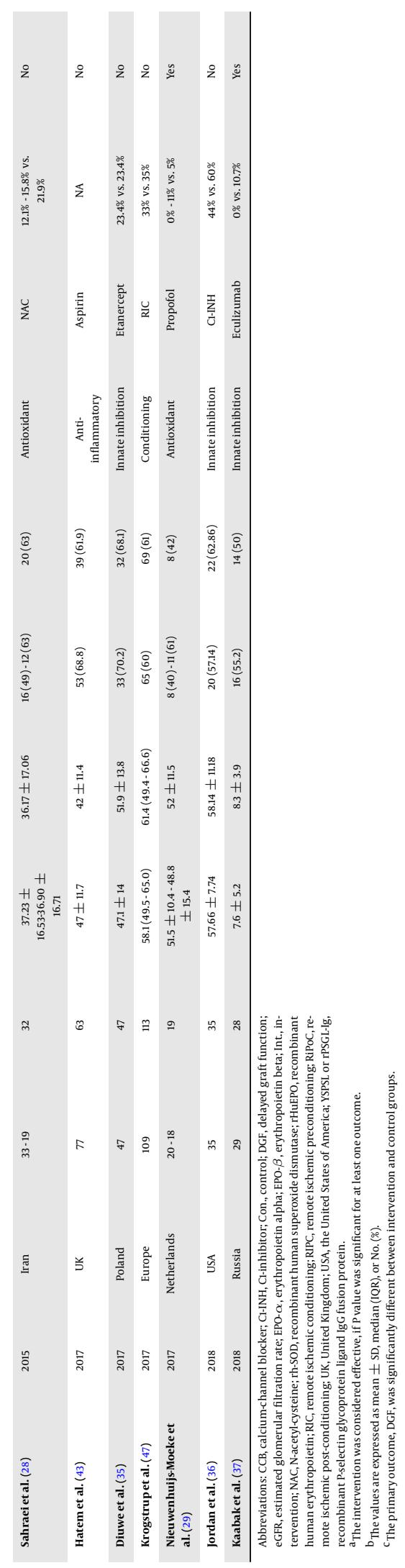




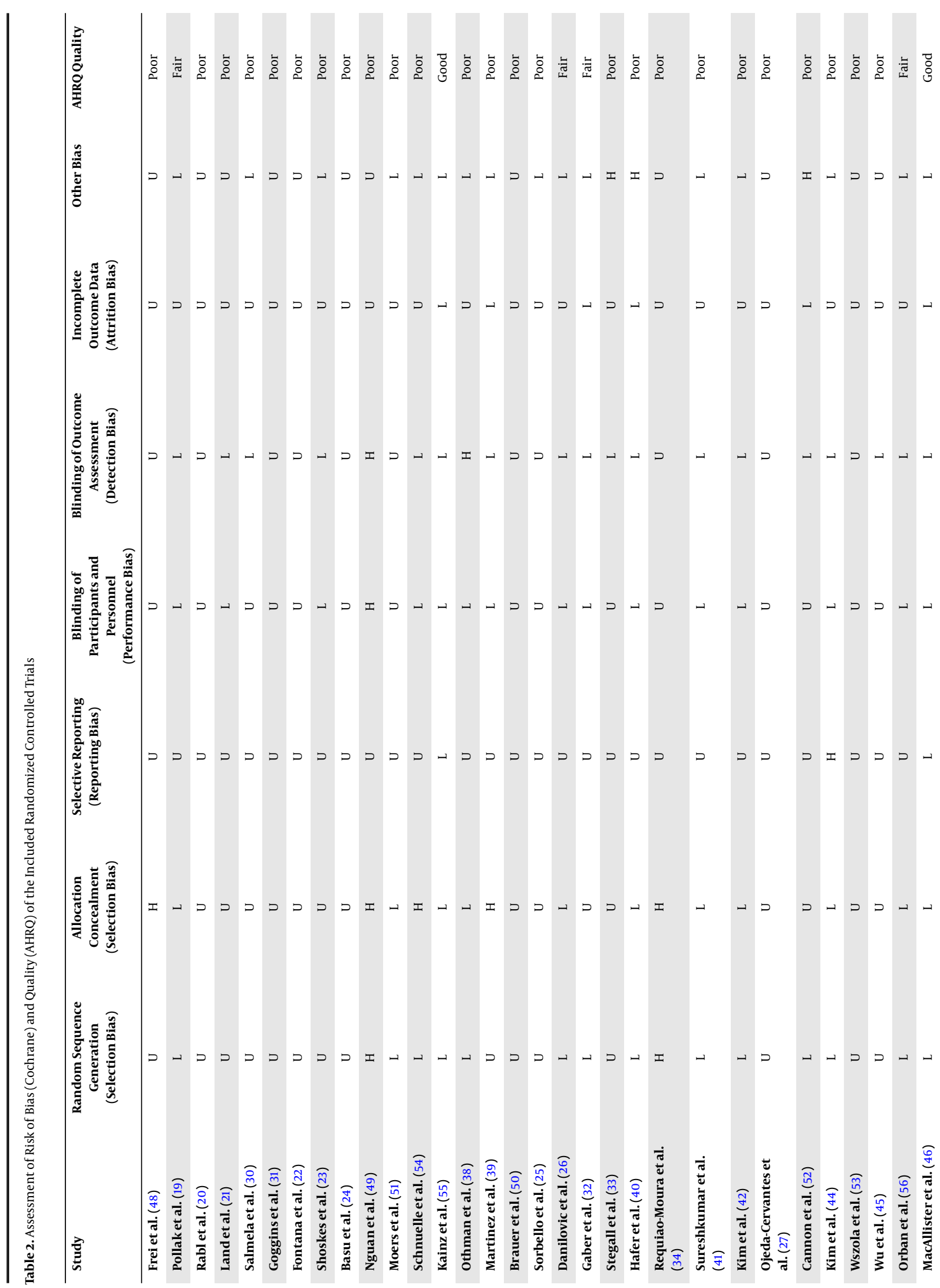




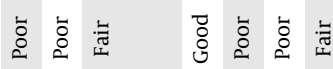

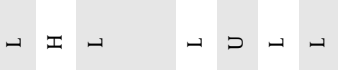

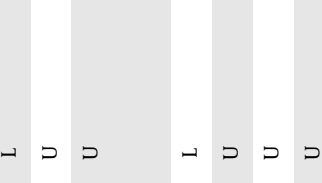

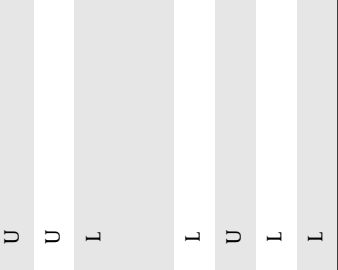

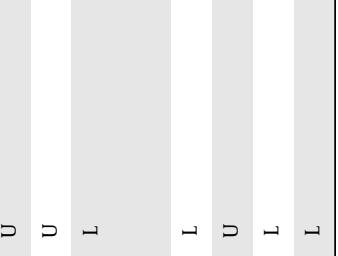

D D D $P$ I

ti

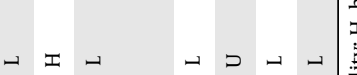

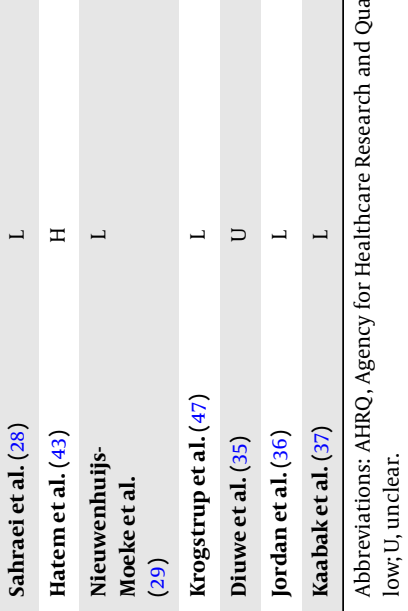

